\section{Estudo \\ CoDebate}

em Testão

Plamejamento
Revista Estudo \& Debate, Lajeado, v. 25, n. 2, 2018. ISSN 1983-036X

DOI: http://dx.doi.org/10.22410/issn.1983-036X.v25i2a2018.1838

\title{
CRESCIMENTO ECONÔMICO E CONVERGÊNCIA DE RENDA NOS MUNICÍPIOS DO RIO GRANDE DO SUL: UMA ANÁLISE DOS TRÊS GRANDES SETORES (2000-2010)
}

\author{
Patricia Batistella ${ }^{1}$, Pascoal José Marion Filho ${ }^{2}$
}

\begin{abstract}
Resumo: $\mathrm{O}$ tema crescimento econômico envolve diversos questionamentos, e o principal deles é o porquê de certas naçóes crescerem mais do que outras. Uma forma encontrada pela literatura para responder tal questionamento é o teste da hipótese de convergência. Buscando avaliar tal fenômeno, o presente trabalho analisa a convergência condicional e absoluta para a taxa de crescimento da renda dos diferentes setores da economia (agropecuário, industrial e serviços) dos municípios do Rio Grande do Sul no decorrer de 2000 a 2010. Além da renda inicial dos setores, foram incluídas as variáveis capital humano, capital físico e aumento da força de trabalho. O ferramental econométrico utilizado para atingir tal objetivo é a econometria espacial, a fim de verificar se o crescimento do PIB (Produto Interno Bruto) dos diferentes setores segue um padrão espacial, ou seja, se tal fenômeno é influenciado pelo espaço. Dessa forma, realizou-se a Análise Exploratória de Dados Espaciais (AEDE). Em seguida, são estimados os modelos econométricos para cada setor, para testar a hipótese de convergência condicional e absoluta. Com AEDE foi possível identificar que a taxa de crescimento do PIB dos setores agropecuário e de serviços são influenciados espacialmente, evidenciando diferentes níveis de associaçóes entre os munícipios gaúchos. O único setor que não apresentou tal característica foi o setor industrial. Os resultados das estimaçóes dos modelos espaciais confirmaram a hipótese de convergência absoluta e condicional para o setor industrial, enquanto que para os demais setores as hipóteses de convergência não foram identificadas.
\end{abstract}

Palavras-chave: Crescimento econômico. Convergência. Econometria espacial. Setores.

1 Economista, Mestre em Economia e Desenvolvimento pela Universidade Federal de Santa Maria (UFSM) e Doutoranda do Programa de Pós-Graduação em Agronegócios da Universidade Federal do Rio Grande do Sul (UFRGS). E-mail: patriciabatistella@rocketmail.com

2 Doutor em Economia Aplicada pela Escola Superior de Agricultura Luiz de Queiroz (ESALQ/ USP). Professor Titular do Departamento de Economia e Relaçôes Internacionais. Professor do Programa de PósGraduação em Administração (PPGA) e do Programa de Pós-Graduação em Economia e Desenvolvimento (PPGE\&D) da Universidade Federal de Santa Maria (UFSM). E-mail: pascoaljmarion@yahoo.com.br 


\title{
ECONOMIC GROWTH AND INCOME CONVERGENCE IN THE MUNICIPALITIES OF RIO GRANDE DO SUL: AN ANALYSIS OF THE THREE MAJOR SECTORS (2000-2010)
}

\begin{abstract}
The theme of economic growth involves several questions, and the main issue is why some nations grow more than others. One way found in the literature to answer such questioning is the test of the convergence hypothesis. The present work analyzes the conditional and absolute convergence for the income growth rate of the different sectors of the economy (agricultural, industrial and services) of the municipalities of Rio Grande do Sul from 2000 to 2010. In addition to income of the sectors, the variables human capital, physical capital and labor force increase were included. The econometric tool used to achieve this objective is spatial econometrics, in order to verify if the growth of GDP (Gross Domestic Product) of the different sectors follows a spatial pattern, that is, if such a phenomenon is influenced by space. In this way, the Spatial Exploratory Data Anlysis (ESDA) was carried out. Next, the econometric models for each sector are estimated, to test the hypothesis of conditional and absolute convergence. With ESDA, it was possible to identify that the GDP growth rate of the agricultural and service sectors is influenced spatially, evidencing different levels of associations between the gaucho municipalities. The only sector that did not present such characteristic was the industrial sector. The results of the estimations of the spatial models confirmed the hypothesis of absolute and conditional convergence for the industrial sector, while for the other sectors the convergence hypotheses were not identified.
\end{abstract}

Keywords: Economic growth. Convergence. Spatial econometrics. Sectors.

\section{INTRODUÇÁO}

O tema crescimento econômico se debruça sobre diversos questionamentos, e o principal deles é o porquê de certas naçóes crescerem mais do que outras. Uma forma encontrada pela literatura para responder tal questionamento é o teste da hipótese de convergência. O primeiro autor a levantar tal hipótese foi Solow (1956). Seu modelo preconiza que no longo prazo as naçóes iriam convergir para um estado estacionário comum, uma vez que as naçôes que inicialmente possuíssem uma renda menor tenderiam a crescer mais que as naçóes com maiores níveis de renda inicial, havendo então uma redução nas disparidades.

Tanto o crescimento econômico como a convergência de renda, são assuntos com uma relação estreita e comumente estudados no campo econômico. Desde os estudos realizados por Baumol (1986) e Abramovitz (1986), com o objetivo de testar a hipótese de convergência de renda em nível mundial, tal tema é aprimorado, tanto no campo analítico quanto no metodológico e teórico.

Além dos níveis de análise, outra característica importante que foi incorporada nos estudos de convergência são os aspectos espaciais, na qual características como localização geográfica passam a ser consideradas. Juntamente com essa análise, surge o interesse em encontrar respostas sobre a influência de uma dada região no desenvolvimento das regiōes vizinhas, através do efeito transbordamento (DA SILVA et al. 2011). As primeiras pesquisas sobre convergência utilizam dados regionais, na maioria das vezes as unidades geográficas eram tratadas como ilhas, não possuindo relação alguma com o seu entorno (QUAH, 1995). Em análogo ao desenvolvimento da literatura sobre convergência, a econometria espacial, especialmente, a partir do trabalho Anselin (1988), muniu o instrumental para lidar explicitamente com esta questáo do espaço. 
O Brasil, sempre foi um país marcado pela desigualdade econômica e social (RANDS, 2011). As regiōes Sul e Sudeste são marcadas por apresentarem indicadores econômicos e sociais superiores às demais regióes do país. O Rio Grande do Sul, especialmente no ano de 2010, possui a quinta maior renda per capita do Brasil (IPEADATA, 2017). Além disso, o Estado se destaca por possuir bons indicadores sociais, mas mesmo assim, não foge dos problemas da desigualdade nos padróes de vida dos distintos estratos de sua população. Enquanto 35\% do PIB do Estado é determinado por cinco cidades, mais de 300 municípios não chegam a representar $0,01 \%$ da produção total do RS (FEE, 2016).

A maior participação no PIB do RS é dada ao setor de serviços, enquanto a menor participação é do setor agropecuário. Conforme dados da FEE (2016), no ano de 2010 o setor de serviços se sobressai como atividade mais importante em cerca de 363 municípios, sendo responsável pela maior parte do valor gerado. Porém, quando é avaliada a estrutura interna de cada município, de forma geral, se distingue da observada para o RS como um todo. Em 111 municípios, a agropecuária é a principal atividade, enquanto em outros 23 municípios a indústria é o destaque.

Não diferente da renda per capita, a participação no Valor Adicionado Bruto (VAB ${ }^{3}$ dos diferentes setores também se concentra em alguns municípios, principalmente os da indústria e de serviços, os quais estão em maior número na Região Metropolitana do Estado.

Dessa forma, buscando contribuir com a literatura desse campo de estudo, o presente trabalho analisa a hipótese de convergência condicional e absoluta para a taxa de crescimento da renda dos diferentes setores da economia (agropecuário, industrial e serviços) dos municípios do Rio Grande do Sul durante o período de 2000 a 2010. Além da renda inicial dos setores, são incluídas as variáveis capital humano, capital físico e aumento da força de trabalho. O ferramental econométrico utilizado para atingir tal objetivo é a econometria espacial.

Após esta introdução a seção dois busca apresentar os fundamentos teóricos relacionados a convergência. A seção três contempla a metodologia utilizada, a apresentação dos dados e do modelo empírico a ser testado. Na quarta seçáo são apresentados os resultados e discussóes do estudo e por fim, as conclusóes.

\section{DEFINIÇÓES DAS HIPÓTESES DE CONVERGÊNCIA}

O Modelo de Solow (1956) constitui um marco importante na performance da renda per capita no longo prazo. O modelo se utiliza de uma função de produção neoclássica, e seu principal pressuposto é de que as economias no longo prazo caminham para steadystate. Para que isso ocorra, é necessário que o crescimento seja impulsionado pela mudança

3 O Valor Adicionado Bruto (VAB) é o valor que cada setor da economia (agropecuária, indústria e serviços) acresce ao valor final de tudo que foi produzido em uma regiáo. O Produto Interno Bruto (PIB) é a soma dos VABs setoriais e dos impostos, e é a principal medida do tamanho total de uma economia (PESSOA, 2017). O PIB citado é a preços de mercado, mas se for calculado a custo de fatores ele é igual ao VAB e a renda interna bruta (RIB) a custo de fatores. Neste trabalho, na parte analítica, o PIB utilizado nos cálculos é igual ao VAB e a RIB 
tecnológica, uma variável exógena ao modelo. É importante destacar que nesse modelo a tendência é de que ocorra convergência de rendas per capita do conjunto de economias para um mesmo nível, a qual ficou conhecida como hipótese de convergência absoluta. Tal processo ocorre quando as medidas que determinam o estado estacionário são análogas, como as taxas de: poupança, progresso técnico e aumento da população (ESPERIDIÂO, 2008).

Alguns fatores apresentados no modelo de Solow (1956) são tidos como responsáveis por acelerar o processo de convergência. O primeiro deles está relacionado ao fato das economias mais pobres possuírem um valor mais baixo de $k$ (capital por trabalhador) e a mobilidade de capital dos países ou regiôes implica que o mesmo passará das economias mais ricas para as mais pobres, fazendo com que as economias mais pobres alcancem mais rapidamente os valores de $k$ e $Y$ (renda) do estado estacionário (BARRO; SALA-I-MARTIN, 1990).

Barro e Sala-i-Martin (1991, 1992), embasados no modelo de Solow (1956), buscam demonstrar de forma algébrica uma alternativa de medir a convergência, o que até então só havia sido proposto graficamente. Os mesmos foram precursores ao adotar e utilizar três definiçóes distintas de convergência: a absoluta, a condicional e a sigma-convergência. A primeira, convergência absoluta ( $\beta$ - convergência) proposta no modelo neoclássico, considera que as economias atrasadas tendem a crescer a taxas mais elevadas do que as economias ricas, e que os países mais pobres acabam alcançando o nível de renda per capita dos países ricos. No entanto, tal definição apresenta um problema ao julgar que tanto os países ricos como os pobres possuem idênticas tecnologias, preferências, instituiçóes, políticas e outras características econômicas, ou seja, que essas economias tenderiam para um mesmo nível de estado estacionário.

A fórmula determinada por Barro e Sala-i-Martin $(1991,1992)$ é representada pela Equação 1:

$$
\ln \left(\frac{Y_{i, t}}{Y_{i, t-1}}\right)=\alpha+\beta \ln \left(Y_{i, t-1}\right)+\varepsilon_{i, t}
$$

$\ln \left(\frac{Y_{i, t}}{Y_{i, t-1}}\right)$ corresponde à taxa de crescimento do produto per capita, $\alpha$ é o intercepto e $\ln \left(Y_{i, t-1}\right)$ representa o logaritmo natural do produto per capita no ano inicial. O termo $i$ corresponde à regiáo, $t$ ao tempo e $\varepsilon$ ao termo de erro.

Dessa forma, para que haja convergência de renda entre os países ou regiôes é necessário que o coeficiente $\beta$ seja negativo, demonstrado com isso uma relação negativa entre a renda per capita inicial com a sua taxa de crescimento (SALA-I-MARTIN, 1992).

A hipótese de rendimentos decrescentes do capital é tida nos modelos de crescimento exógenos como o principal fator que contribuiu para a ocorrência de convergência de renda entre as naçóes. Contrapondo tal argumento, a teoria do crescimento endógeno surge com o objetivo de destacar a ausência dos rendimentos marginais decrescentes dos fatores de produção, renovando o interesse dos pesquisadores sobre a hipótese ou não de convergência. 
Assim, com vistas a mesurar e testar a hipótese, a literatura do crescimento econômico buscou apresentar algumas alternativas, como a hipótese de convergência condicional.

A hipótese de convergência condicional leva em consideração que cada economia seria detentora de seus próprios parâmetros, o que significa que cada uma delas apresentaria um nível próprio de steady-state, havendo assim convergência condicional.

Conforme observado por Sala-i-Martin (1992), caso as disparidades na renda per capita não sejam a única diferença entre países ou regióes, a hipótese de convergência absoluta não seria sustentada. Em um primeiro momento, as economias não tenderiam a evoluir para um estado estacionário comum, mas sim para o seu próprio equilíbrio. Além disso, o processo de convergência absoluta não leva em consideração variáveis que podem influenciar ou não a aceleração do processo de convergência.

Diante de tais suposiçóes e com o advento das novas teorias do crescimento econômico, a representação matemática a fim de testar a hipótese convergência condicional passa a ser a Equação 2:

$$
\ln \left(\frac{Y_{i, t}}{Y_{i, t-1}}\right)=\alpha+\beta \ln \left(Y_{i, t-1}\right)+X_{i, t} \theta+\varepsilon_{i, t}
$$

de modo que $\ln \left(\frac{Y_{i, t}}{Y_{i, t-1}}\right)$ representa à taxa de crescimento da renda per capita (variável dependente), $\alpha$ é a constante, $\beta$ é o parâmetro que acompanha a variável $Y_{i, t-1}$, a qual representa a renda per capita inicial, $X_{i, t}$ é a matriz das variáveis de controle que podem ser incluídas no modelo, $\theta$ é o vetor dos coeficientes da matriz , $\varepsilon$ é o termo de erro aleatório e $i$ e $t$ representam as regióes e o período, respectivamente.

De maneira análoga ao modelo de convergência absoluta, a expectativa é que o $\beta$ seja negativo, indicando assim a existência de convergência condicional, sendo possível inferir que os países ou regióes, de acordo com suas características, estão alcançando o seu próprio estado estacionário.

Sucintamente, a convergência condicional prediz, ao contrário da convergência absoluta, que as economias nacionais ou regionais tendem para uma posição de equilíbrio no longo prazo, e que, por apresentarem diferentes estados estacionários, suas desigualdades em termos de renda per capita deverão persistir, admitindo assim a possibilidade de divergência

Dessa forma, com base na literatura teórica e empírica apresentada, o trabalho traz a evolução desses aspectos tanto no incremento das variáveis utilizadas neste estudo como também na metodologia, as quais são apresentadas a seguir.

\section{METODOLOGIA}

Com a finalidade de realizar uma análise prévia dos dados e também identificar a existência do efeito transbordamento do crescimento econômico nos municípios do RS, utiliza-se a técnica de Análise Exploratória de Dados Espaciais (AEDE) e posteriormente, a estimação de modelos econométricos espaciais empregados para testar a hipótese de convergência absoluta e condicional. 


\subsection{Análise exploratória de dados espaciais}

A análise exploratória de dados espaciais (AEDE) constitui um conjunto de técnicas que tem por finalidade identificar e descrever distribuiçôes espaciais, buscando detectar a existência ou não de localizaçóes espaciais atípicas: outliers, padróes de associação espacial, a formação de clusters, ou demais formas de heterogeneidade espacial (BAUMONT; ERTUR; LE GALLO, 2000).

O primeiro passo a ser realizado num estudo com a utilização da AEDE é testar a hipótese de que os dados sejam distribuídos aleatoriamente, contra a hipótese alternativa de que haja dependência espacial. A aleatoriedade espacial supóe que os valores de uma característica de determinada regiáo não dependem dos valores das mesmas características das regiôes contíguas. Tal hipótese é verificada através das estatísticas de autocorrelação espacial (ALMEIDA, 2012).

A autocorrelação espacial global pode ser definida como a coincidência de similaridade de valor com similaridade locacional. Dessa forma, não haverá autocorrelação espacial positiva quando altos ou baixos valores de uma variável aleatória aglomeram-se no espaço, e não há autocorrelaçáo espacial negativa quando áreas geográficas tendem a ser cercadas por vizinhos com valores muito diferentes (BAUMONT; ERTUR; LE GALLO, 2000).

A estatística de autocorrelação espacial é resultante da composição de três elementos: uma medida de autocovariância, uma medida de variância dos dados e da matriz de ponderação espacial $(\boldsymbol{W})$. As principais medidas adotadas na literatura para obtenção das medidas de autocovariância são a estatística $I$ de Moran, estatística de $c$ de Geary e estatística G de Getis-Ord (ALMEIDA, 2012).

A estatística $I$ de Moran foi desenvolvida por Moran em (1948), e é a mais utilizada. Moran (1948) construiu um coeficiente de autocorrelação espacial utilizando a medida de autocovariância na forma de produto cruzado. Matricialmente a estatística é dada por:

$$
I=\frac{n}{S_{0}} \frac{Z^{\prime} W_{Z}}{Z^{\prime} Z}
$$

onde $n$ é o número de regióes, $Z$ denota os valores da variável de interesse padronizada, $W_{Z}$ representa os valores médios da variável de interesse padronizada dos vizinhos, os quais são definidos por uma matriz de ponderação espacial $W . S_{o}$ representa a operação $\Sigma_{i} \Sigma_{j} W_{i j}$, indicando que todos os elementos da matriz de pesos espaciais $W$ devem ser somados. O termo do numerador $Z^{\prime} W_{Z}$ é a autocovariância espacial (ALMEIDA, 2012).

Dessa forma, a hipótese nula a ser testada é a de aleatoriedade espacial, sendo que o valor esperado pelo $I$ de Moran é dado por $-1[1 /(n-1)]$, o qual é obtido caso não haja padrão espacial nos dados. Os valores do $I$ de Moran superiores a $-1[1 /(n-1)]$ indicam que há autocorrelação espacial positiva, ou seja, altos valores em uma determinada região são incorporados por vizinhos com características semelhantes. $\mathrm{O}$ índice menor que o valor crítico sugere que existe autocorrelação espacial negativa, ou seja, altos valores estão localizados perto de valores baixos, ou vice-versa. 
Conforme Almeida (2012), para a implementação da AEDE é necessário que, primeiramente, seja definida uma matriz de pesos espaciais $(\boldsymbol{W})$. Tal matriz é responsável por apresentar os arranjos espaciais das interaçóes resultantes do fenômeno que está sendo estudado. Em suma, a matriz ( $W$ ) contém a informação do quanto a interação é mais forte no caso das regióes mais próximas geograficamente ou socioeconomicamente, e mais fraca nas regiôes mais distantes. Essa matriz tem por finalidade capturar toda a autocorrelação espacial presente no fenômeno estudado, e é uma matriz quadrada de dimensão $n$ por $n$, e os pesos espaciais $W_{i j}$ representam a influência do município $j$ sobre o município $i$. Assim, por convenção $W_{i i}$, é igual a zero.

A matriz utilizada poderá assumir diferentes formas, por contiguidade, a qual assume a ideia de fronteira física, ou seja, caso dois municípios partilhem de uma fronteira física comum os mesmos são contíguos, e podem ser de três tipos: rainha (queen), torre (rook) e bispo (bishop). A construção da matriz de pesos espaciais é binária, assumindo valores unitários e nulos. Além disso pode ser testada também por proximidade entre uma região definida pela distância geográfica, medida em quilômetros ou milhas ou proximidade socioeconômica.

\subsection{Modelo Econométrico espacial}

Ao especificar um modelo espacial o pesquisador deve levar em consideração os aspectos teóricos e empíricos que estão por trás do fenômeno estudado. Almeida et al. (2008) destacam que a definiçáo de um modelo para captar questóes inerentes a efeitos de transbordamento entre as regióes deve considerar explicitamente componentes espaciais em sua forma funcional. Os modelos econométricos lineares não compreendem os efeitos que são incorporados pela modelagem espacial, como a dependência e heterogeneidade espacial.

Assim, quando um modelo possui em seu contexto teórico e empírico a influência do espaço, o melhor método a ser utilizado é aquele em que possibilita capturar e mensurar os efeitos espaciais. A Equação 3 representa matricialmente um modelo de regressão linear clássico, ou seja, um processo a-espacial.

$$
\mathbf{y}=\mathbf{x} \boldsymbol{\beta}+\varepsilon
$$

onde $\mathbf{y}$ é um vetor $n$ por 1 de observações da variável dependente, $\boldsymbol{X}$ é uma matriz $n$ por $k$ de observaçóes sobre as variáveis explicativas exógenas mais a constante, $\beta$ é o coeficiente de regressão e $\varepsilon$ é um vetor $n \times 1$ de termos de erro aleatório, com média zero e variância constante.

As classificaçóes dos modelos espaciais apresentados em seguida são propostos por Anselin (1988), Anselin e Bera (1998), Florax e Folmer (1992) e LeSage e Pace (2009). A fim de controlar a dependência espacial, os autores incorporam no modelo apresentado na Equação 21 as defasagens espaciais. As defasagens espaciais ganham forma no modelo por meio de uma variável defasada espacialmente. A defasagem pode ser incluída na variável dependente $(W)$, nas variáveis independentes $(W X)$ e/ou defasagem nos termos de erros $\left(W_{\varepsilon}\right)$ (ALMEIDA, 2012). Além disso, os modelos podem ser classificados também pelo alcance de seu efeito transbordamento, seja ele global ou local. 
Com a finalidade de obter especificaçâo do modelo mais adequada é necessário seguir alguns passos. Primeiramente, deve ser estimado o modelo via o método dos Mínimos Quadrados Ordinários (MQO), sendo possível testar a hipótese de autocorrelaçáo espacial a partir do erro ou da defasagem espacial. Caso os testes não apresentem significância, o modelo com maior ajuste é o de regressão clássico por $\mathrm{MQO}$, porém se os parâmetros são significativos é necessário averiguar a versấo robusta dos testes e analisar a significância estatística para o uso de um modelo de erro espacial ou de defasagem espacial (ALMEIDA, 2012).

\subsubsection{Base e fonte de dados}

Os dados utilizados na pesquisa são referentes aos 469 municípios do Rio Grande do Sul, o número de municípios emancipados no ano de 2000. Optou-se por trabalhar com está base pelo fato de utilizar a taxa de crescimento, sendo necessário o mesmo número da amostra no período inicial e final.

A variável dependente (TAXCRES) é resultante do logaritmo natural da razão entre os valores do PIB no ano de 2010 dividido pelo PIB no período inicial (2000). Para construção dessa variável, utilizou-se o VAB de cada setor. A taxa de crescimento é real, pois os valores correntes do VAB foram deflacionados pelo respectivo deflator implícito, ambos foram obtidos junto a Fundação de Economia e Estatística do Rio Grande do Sul (FEE). Matematicamente, a construção da variável é dada pela seguinte forma:

$\mathrm{TAXCRE}_{i t}=\ln \left(\right.$ PIB $_{i t} /$ PIB $\left._{(i t-1)}\right)$.

A variável explicativa, PIB inicial $\left(P I B_{t-1}\right)$, se dá a partir do logaritmo natural da variável no período inicial. O PIB inicial é incluído para que se possa testar a hipótese de convergência. Para que a mesma possa ser aceita é necessário que o coeficiente $\beta$ seja estatisticamente significativo e apresente sinal negativo. $\mathrm{O}$ valor de tal variável corresponde ao VAB de cada setor no período inicial.

A variável capital físico é mensurada pela proxy consumo de energia elétrica dos diferentes setores, em megawatt elétrico (MWe), obtido junto a FEE. Além disso, os dados foram ponderados pelo consumo total de energia de cada município.

A taxa de crescimento da população, a qual foi obtida através da seguinte representação

matemática $\left[\left(\sqrt[n]{\frac{P o_{i t}}{P_{t-1}}}\right)-1\right] \times 100$, onde; $n$ representa o número de anos do período; $P o_{i t}$ população ocupada no ano de 2010 ; e $P o_{t-1}$ população ocupada no período inicial 2000 foi construída pelo número de pessoas ocupadas em cada setor durante 2000 e 2010, disponível junto ao censo demográfico do IBGE.

A variável utilizada para mensurar o capital humano é o logaritmo natural da razão entre o número pessoas ocupadas que possuem no mínimo ensino fundamental completo nos diferentes setores. Os dados foram extraídos junto aos censos demográficos (IBGE). Os modelos de crescimento endógenos, principalmente o de Lucas (1988), enfatiza a existência de externalidades positivas geradas pelo capital humano. 
Com a finalidade de testar a hipótese de convergência absoluta, o modelo é estimado com base em Baumol (1986) e com algumas modificaçóes realizadas por Ribeiro (2010). Dessa forma, a especificação é a seguinte:

$$
\text { TAXCRES }_{\text {sit }}=\beta_{0}+\beta_{1} \ln \left(P I B_{\text {sit }-1)}+\varepsilon_{i}\right.
$$

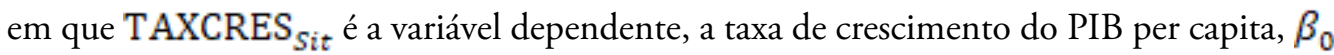
corresponde ao intercepto, $P I B_{i t-1}$ é o logaritmo natural da variável PIB no período inicial, o subscrito $s$ tem por finalidade representar os diferentes setores, o termo $i$ os municípios e o período é representado por $t$, e $\varepsilon_{i}$ corresponde aos componentes dos erros aleatórios . O modelo especificado na Equaçáo 5 é estimado para cada setor (agropecuário, industrial e serviços).

A estimação do modelo de convergência condicional tem a seguinte especificaçáo econométrica:

$$
\text { TAXCRES }_{s i t}=\beta_{0}+\beta_{1} \ln P I B_{s i t-1}+\beta_{2} K_{s i t}+\beta_{3} N_{s i t}+\beta_{4} \ln H_{s i t}+\varepsilon_{i}
$$

onde TAXCRES T $_{t}$ é a variável dependente representando a taxa de crescimento do PIB por setor, $\beta_{0}$ corresponde ao intercepto, $P I B_{i t-1}$ o logaritmo natural da variável PIB por setor no período inicial; $K_{i t}$ corresponde ao capital físico; $N_{i t}$ corresponde a taxa de crescimento da população; $H_{i t}$ é a variável capital humano, o termo $i$ os municípios, o período é representado por $t$, e $\varepsilon_{i}$ sáo os erros aleatórios.

\section{RESULTADOS E DISCUSSÃO}

A AEDE constitui um passo importante na análise de dados espaciais, pois através desse ferramental é possível detectar a presença de outliers globais e espaciais bem como pontos de alavancagem. As principais técnicas utilizadas na AEDE são a autocorrelação local e global, nos contextos univariado e bivariado. Nesse trabalho, as duas técnicas são utilizadas com as seguintes variáveis: taxas de crescimento do PIB nos diferentes setores e também o PIB dos mesmos no período inicial, durante os anos de 2000/2010.

Os diagramas de dispersão de Moran são apresentados na Figura 1, nos quais é possível verificar a presença da autocorrelação espacial. Tal diagrama busca relacionar a variável que está sendo analisada com ela própria, só que defasada espacialmente. Após está estimação, os dados são agrupados nos quadrantes Alto-Alto (AA), Baixo-Baixo (BB), AltoBaixo (AB) e Baixo-Alto (BA), de acordo com seu grau de associação. 
Figura 1 - Diagrama de dispersão de Moran univariado para a taxa de crescimento do PIB dos setores agropecuário, industrial e serviços

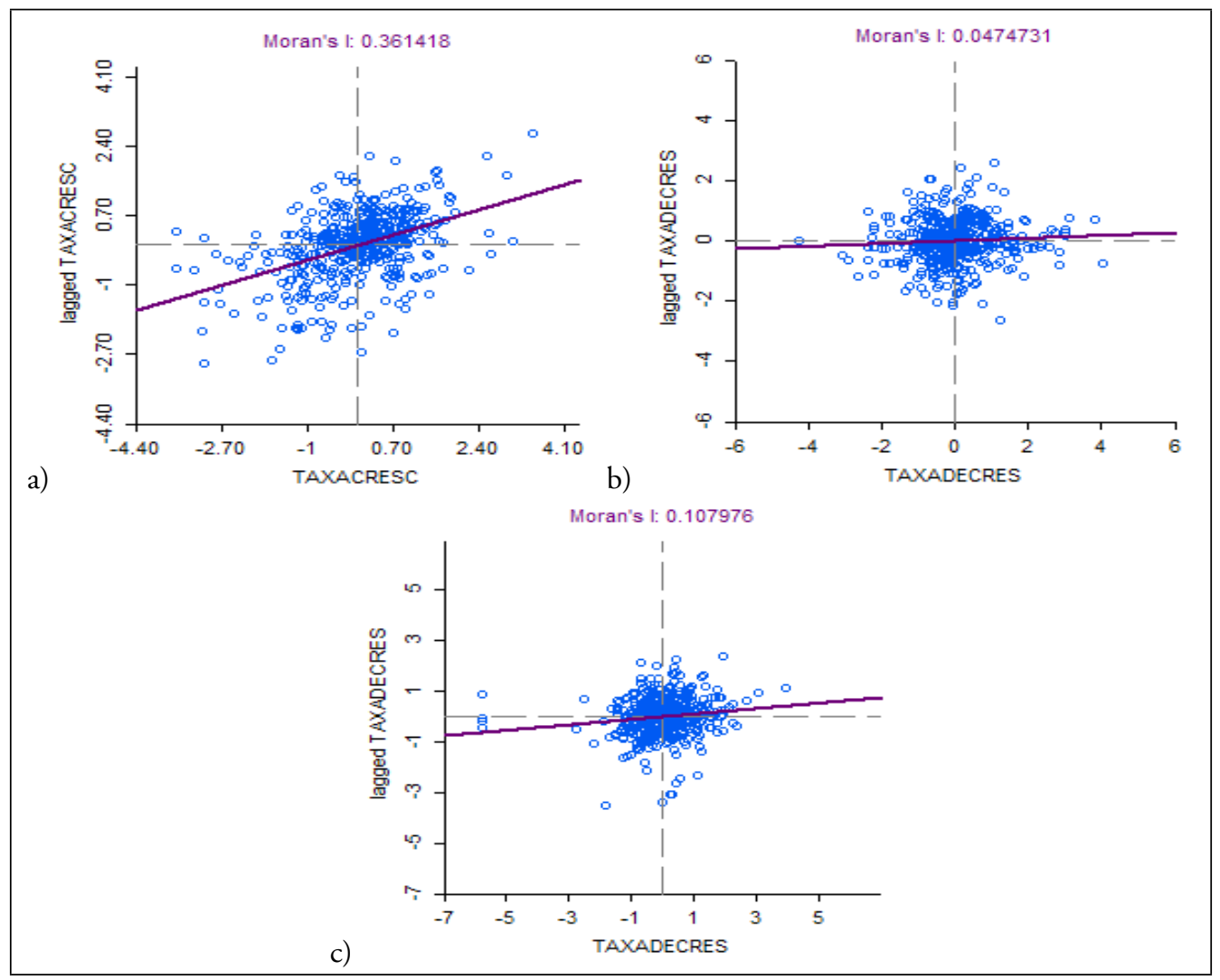

Fonte: Elaborada com resultados da pesquisa através do Software GeoDa (versão 1.8.16.4).

Obs: Estatística $I$ de Moran calculado com a matriz $k=2$ e pelo critério de 999 permutaçóes.

Ao observar o diagrama, seja pela inclinação da reta ou pelo valor da estatística $I$, a variável analisada apresentou dependência espacial, para o setor agrícola (Figura a). Além disso, a autocorrelação é positiva dado que o valor do $I$ de Moran obtido é maior que o valor esperado da estatística $(-0,0021)$. O fato de apresentar autocorrelaçáo positiva indica que os municípios seguem um mesmo padrão de crescimento, no qual municípios com taxa de crescimento alta são vizinhos de municípios que apresentam também uma taxa elevada de crescimento. Percebe-se ainda que há uma maior concentração dos municípios no quadrante AA (Figura a).

O setor industrial, embora a estatística $I$ de Moran seja maior que o valor esperado, não demonstrou ser significativa nem mesmo ao nível de significância de 10\% (Figura b). Assim, é possível inferir que a mesma não possui dependência espacial. De acordo com Almeida (2012), tal problema acontece principalmente na análise de autocorrelação global, que apesar de ser útil, em alguns casos a mesma não apresenta significância estatística. Diante de tais problemas, sugere-se entáo que seja realizada a análise de autocorrelaçáo local, a fim de detectar a existência de padróes locais espaciais. 
O digrama de dispersão apresentado na (Figura c) é resultante da regressão da taxa de crescimento do PIB do setor de serviços (no eixo horizontal) contra a mesma variável defasada espacialmente (no eixo vertical). $\mathrm{O}$ valor $I$ de Moran para o setor de serviços apresentou significância estatística, o que leva a concluir que a taxa de crescimento do seu PIB possui dependência espacial. Além disso, a autocorrelaçáo positiva $(0,107976)$ indica que a taxa de crescimento do setor é positivamente relacionada com a taxa de crescimento dos municípios vizinhos, ou seja, as características existentes em um determinado município seguem o mesmo padrão de seu município vizinho. Tal estatística aponta que municípios com elevada taxa de crescimento no setor de serviços tendem a estar cercados por municípios com taxa de crescimento também elevada. Para aqueles com baixa taxa de crescimento, temse também a mesma relação.

Com o intuito de identificar se o processo de convergência de renda dos diferentes setores apresenta algum padráo de dependência espacial, fez-se a análise de autocorrelação global bivariada. Na quantificação são regredidas as taxas de crescimento do PIB dos setores contra o seu respectivo PIB no período inicial, os quais são apresentados na Figura 2.

Figura 2 - Diagrama de dispersão de Moran bivariado para o PIB inicial e taxa de crescimento dos três setores: agropecuário (a), indústria (b) e serviços (c)

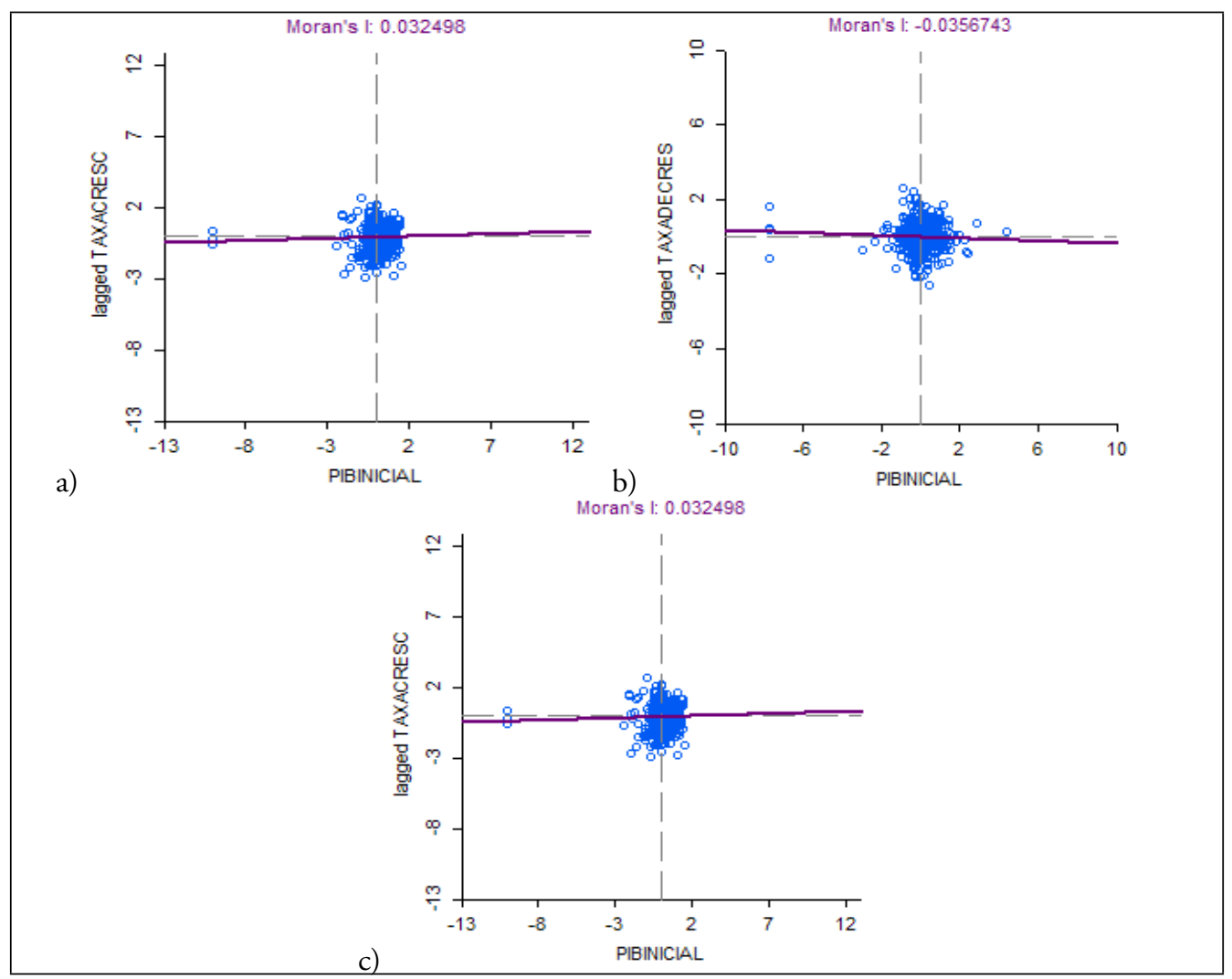

Fonte: Elaborada com resultados da pesquisa através do Software GeoDa (versão 1.8.16.4).

Obs: Estatística $I$ de Moran calculada com a matriz $k=2$ e pelo critério de 999 permutaçóes. 
Embora a estatística não apresente significância, é possível observar na Figura 2 para os setores industrial (b) e de serviços (c), que a estatística $I$ de Moran apresentou correlação negativa, ou seja, os municípios com uma taxa de crescimento elevada possuem vizinhos com uma renda inicial baixa.

A fim de detectar a autocorrelação local, foram calculadas as estatísticas de $I$ de Moran local para as variáveis supracitadas. A apresentação dos resultados é dada em forma de mapa cluster LISA, conforme a Figura 3. O mapa de agrupamentos LISA combina as informaçôes do diagrama de dispersão de Moran e a significância dos grupos locais de $I$.

Como já mencionado na seção metodológica, a técnica de autocorrelação local capta apenas os municípios que foram significativos estatisticamente. No caso desse estudo, o nível de significância adotado para todas as variáveis foi de $5 \%$.

Figura 3 - Mapa Cluster LISA para a taxa de crescimento do PIB dos setores agropecuário (a), industrial (b) e serviços (c)

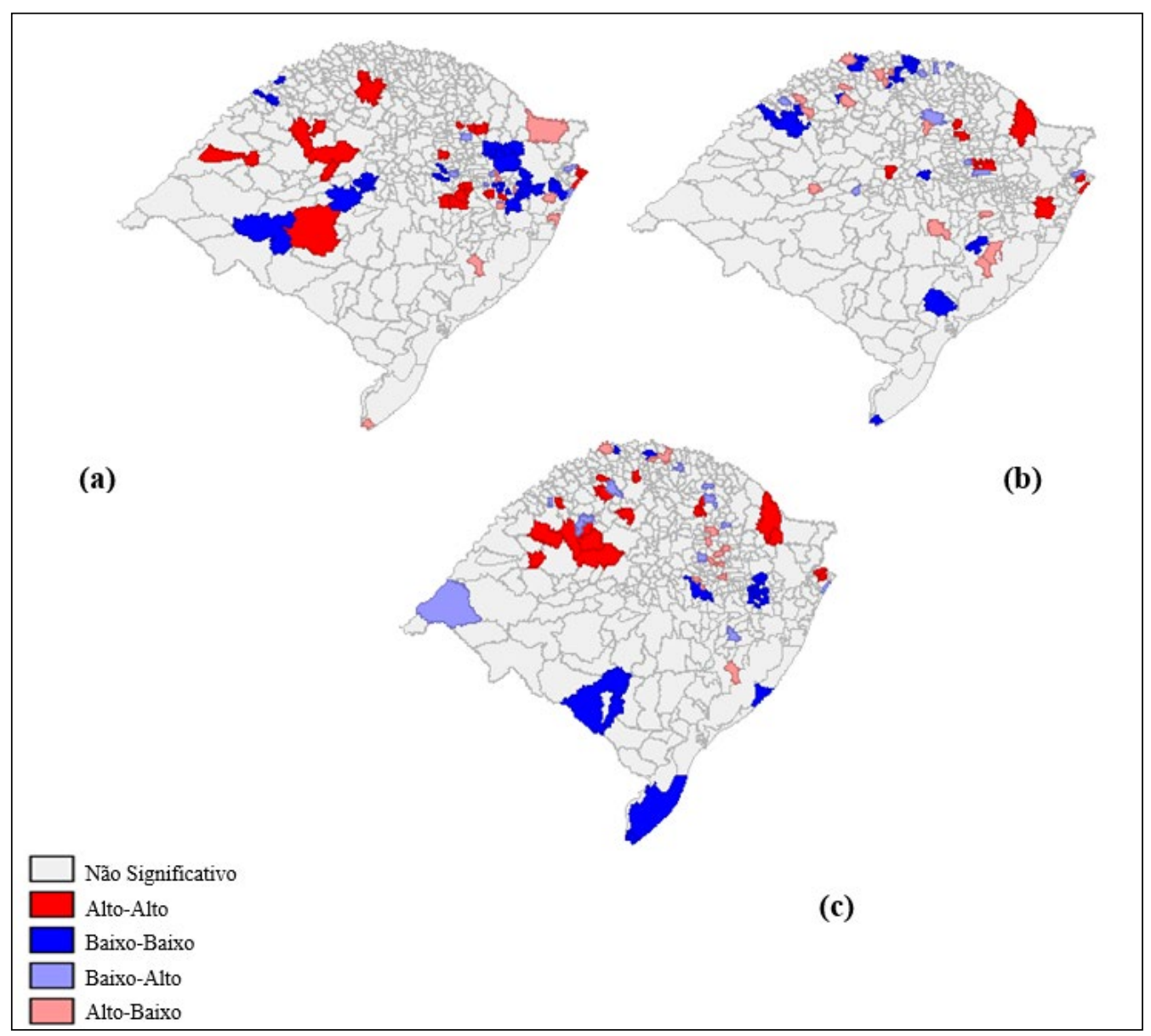

Fonte: Elaborada com resultados da pesquisa através do Software GeoDa (versão 1.8.16.4). 
A Figura a, aponta para a formação de seis clusters localizados no quadrante Alto-Alto (AA), demarcados pela cor vermelha. Os mesmos são compostos por dezenove municípios espalhados nas diferentes microrregióes do Estado: Santiago, Cruz Alta, Carazinho, São Gabriel, Campanha Ocidental e Lajeado-Estrela. Como é possível perceber, a maioria dos clusters no quadrante AA estão localizados na metade Norte do RS. A autocorrelaçáo espacial positiva indica que os municípios localizados nesses clusters possuem vizinhos com alta taxa de crescimento do PIB do setor agropecuário.

As microrregiôes de Cruz Alta e Carazinho, enquadradas no cluster AA, possuem participação significativa na produção de soja no Estado, enquanto que as microrregióes da Campanha Ocidental e de Santiago são expressivas na produção agropecuária (FEE, 2017).

Em relação a taxa de crescimento do PIB industrial, é possível identificar que poucos municípios foram significativos ao nível de $5 \%$ (Figura b). No quadrante AA, identificado pela cor vermelha intensa, no total formaram quatro grupos compostos por dez municípios, localizados nas microrregiôes de Vacaria, Porto Alegre e Guaporé. A região Metropolitana do Estado é a que mais possui participaçáo no VAB industrial, tendo como destaques a capital Porto Alegre, Canoas e Novo Hamburgo (FEE, 2017). A autocorrelação local indicou que os municípios pertencentes a este cluster possuem alta taxa de crescimento no setor e são vizinhos de municípios com a mesma característica.

O mapa cluster LISA da taxa de crescimento do PIB no setor de serviços, apresentou três clusters maiores no quadrante AA (Figura c). Os mesmos abrangem o total de vinte municípios, localizados nas microrregióes de Cruz Alta, Santo Ângelo e Vacaria. O setor de serviços apresentou uma taxa média de crescimento superior no período analisado aos demais setores do Estado.

No que tange ao quadrante $\mathrm{BB}$, também é possível perceber a formação de três principais clusters, os quais abrangem vinte e três municípios. A localizaçâo dos mesmos se dá, principalmente, na Região Sul do Estado e na Campanha, e alguns esparsos na região Centro-Oeste. Diferentemente do padrão de associação do cluster AA, os municípios deste quadrante $\mathrm{BB}$ obtiveram taxas de crescimento menores do que a média total do Estado.

A Figura 4 traz os mapas LISA clusters para análise bivariada. Através do mesmo é possível verificar se municípios com uma alta taxa de crescimento possuem vizinhos com PIB inicial elevado, ou vice versa. O primeiro mapa (a) representa a localizaçáo dos clusters para o setor agropecuário, e os mapas (b) e (c), os setores industrial e de serviços, respectivamente. 
Figura 4 - Mapa Cluster LISA Bivariado para a taxa de crescimento do PIB e PIB inicial dos setores: agropecuário (a), indústria (b) e serviços (c)

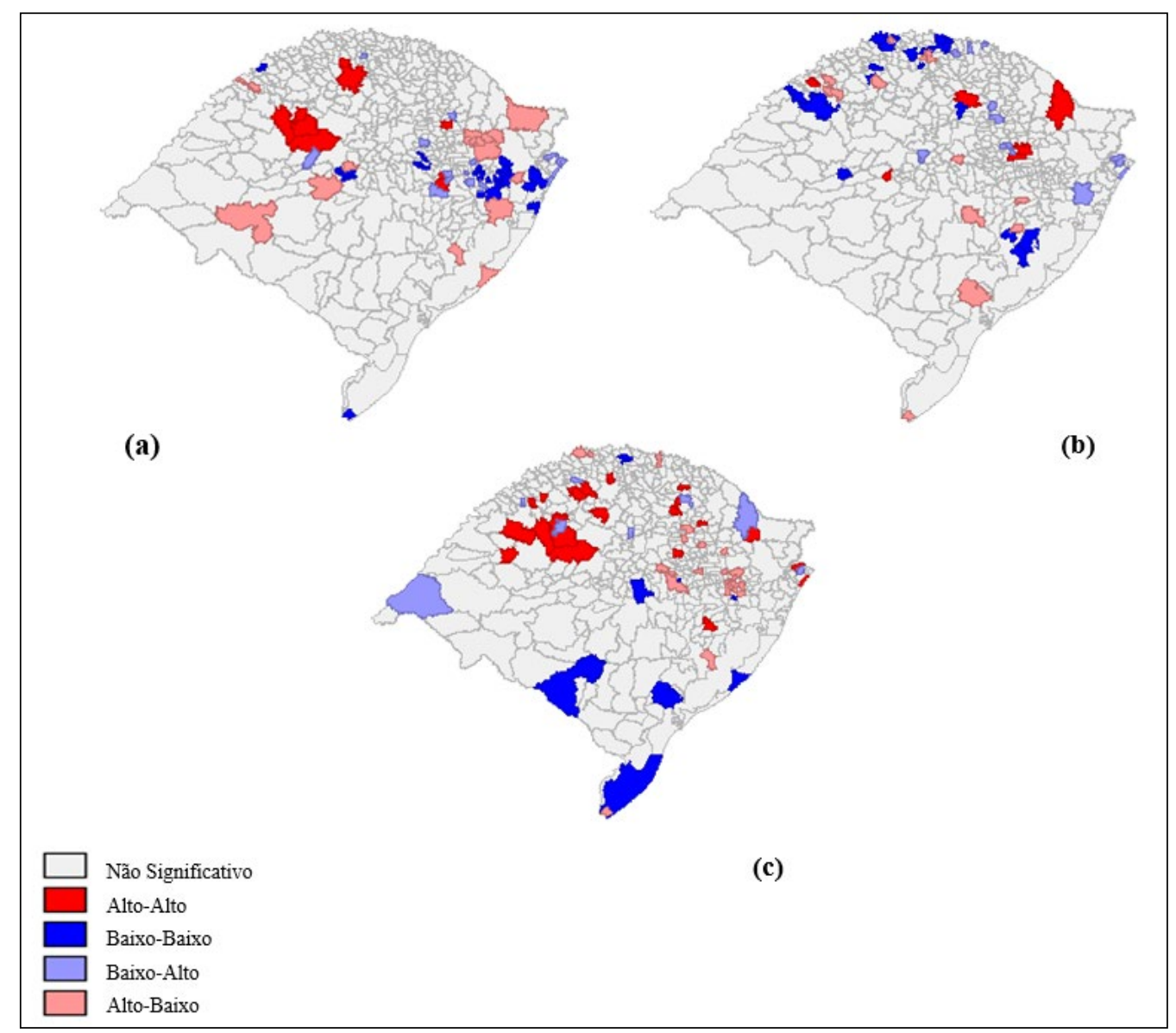

Fonte: Elaborada com resultados da pesquisa através do Software GeoDa (versão 1.8.16.4).

Através da visualização dos três mapas da Figura 4, é possível identificar que poucos municípios foram significativos. Observando os quadrantes AA, pode-se inferir que municípios com altas taxas de crescimento possuem vizinhos com renda inicial alta. Esse padrão de associação é verificado principalmente no setor de serviços (Mapa c), onde os agrupamentos ocorreram nas mesmas regióes da análise univariada (Regiáo Noroeste). Tal resultado se deu pelo fato do setor de serviços estar presente com mais intensidade em um número maior de municípios do que os demais setores.

No setor industrial (Mapa b), o maior número de municípios significativos se enquadraram no quadrante $\mathrm{BB}$, totalizando cerca de dezoito municípios. O quadrante $\mathrm{BB}$ agrupou municípios que possuem baixa taxa de crescimento com vizinhos que possuem uma renda inicial baixa também. Ao analisar os dados desses municípios é possível verificar que alguns apresentaram taxa de crescimento negativo, como é o caso de Ubiretama, localizado 
na região Noroeste do Estado. Os demais, como Cerro Largo e Campinas das Missóes, obtiveram uma taxa de crescimento abaixo de $1 \%$ ao ano.

Um fato importante detectado através da AEDE é que a metade Sul do Estado não apresenta nenhum setor com taxa de crescimento no padrão $A A$, ou seja, municípios detentores de altas taxas de crescimento vizinhos de municípios com as mesmas características. A perda de dinamismo na Região Sul do RS já vem sendo abordada em diversos estudos no Estado, conforme Menezes e Feijó (2008), e mostram que o desequilíbrio regional no Rio Grande do Sul evoluiu no decorrer do século XX. De certa forma, os papéis quanto à hegemonia e à dinâmica econômica regional inverteram-se. A região Sul possui na concentração da riqueza um dos principais fatores que dificultam seu crescimento (predomina os latifúndios pecuários), e entre as diferenças mais acentuadas entre as regiōes está a especialização no setor industrial, mais desenvolvido na região Nordeste.

Através da análise exploratória desenvolvida neste capítulo, é possível verificar que os setores agropecuários e de serviços possuem uma dependência espacial maior do que o setor industrial. Tais resultados contribuem para a estimação dos modelos econométricos espaciais apresentados em seguida.

\section{2 Estimaçóes e Análises dos modelos Econométricos Espaciais}

Os primeiros resultados apresentados são os modelos estimados com o objetivo de testar a hipótese de convergência absoluta. Para tanto, conforme já destacado na seção metodológica, o primeiro passo consiste em estimar o modelo por MQO (Mínimos Quadrados Ordinários). Caso a hipótese de aleatoriedade espacial seja rejeitada, segue-se a estimação dos modelos espaciais.

A identificação do processo espacial pelo qual o fenômeno analisado está autocorrelacionado espacialmente, seja pela defasagem da variável dependente ou pela dependência espacial na forma residual, se dá através dos testes focados do tipo Multiplicador de Lagrange. $\mathrm{Na}$ Tabela 1, apresentam-se os modelos para os três setores estimados por MQO. A mesma traz os coeficientes, a probabilidade ( $p$-valor) e as estatísticas dos testes. 
Tabela 1 - Resultados dos Modelos estimados por MQO para os setores agropecuário, industrial e serviços, para a hipótese de convergência absoluta

\begin{tabular}{llll}
\hline Variáveis & Agropecuário & Industrial & Serviços \\
\hline Variável & & & \\
dependente: & $\ln \left(P I B_{i t} / P_{(i t-1)}\right)$ & $\ln \left(P I B_{i t} / P I B_{(i t-1)}\right)$ & $\ln \left(P I B_{i t} / P I B_{(i t-1)}\right)$ \\
\hline Constante & 0,809059 & 2,1696 & 0,872992 \\
PIB Inicial (2000) & $(0,00000)$ & $(0,00000)$ & $(0,00000)$ \\
& 0,0301097 & $-0,069014$ & 0,0934381 \\
\hline AIC & $(0,00423)$ & $(0,02517)$ & $(0,00000)$ \\
SC & 358,156 & 1021,18 & 96,3168 \\
I de Moran & 366,466 & 1029,49 & 104,627 \\
& 0,3625 & 0,0418 & 0,1605 \\
ML- Defasagem & $(0,0000)$ & $(0,29514)$ & $(0,00012)$ \\
& 73,3568 & 1,0931 & 13,8733 \\
MLR - Defasagem & 0,1052 & $(0,29578)$ & $(0,00020)$ \\
& $(0,74571)$ & 0,4980 & 65,8578 \\
ML - Erro & 73,5937 & $(0,48038)$ & $(0,93092)$ \\
& $(0,0000)$ & 0,9826 & 14,4603 \\
MLR - Erro & 0,3421 & $(0,32157)$ & $(0,00014)$ \\
Teste Jarque-Bera & 31,6928 & 0,3874 & 0,5946 \\
ML SARMA & $(0,55864)$ & $(0,53366)$ & $(0,44066)$ \\
Teste Breusch-Pagan & 37,8880 & 1,1871 & 14,6284 \\
& $(0,00000)$ & $(0,55237)$ & $(0,00067)$ \\
& $(0,0000)$ & 12,1254 & 29,5521 \\
& 20,11 & $(0,034677)$ & $(0,00000)$ \\
& 108,1030 & 17,2451 \\
& $(0,0000)^{*}$ & $(0,0000)$ \\
& 15,55 & 27,46 \\
\hline
\end{tabular}

Obs.: * Com o propósito de confirmar a normalidade dos resíduos, o teste Jarque-Bera foi utilizado neste estudo. O teste rejeitou a hipótese nula de normalidade de resíduos. De acordo com Greene (2008), náo é necessário assumir a normalidade de resíduos para grandes amostras. Ainda, Wooldridge (2010) indica que a não rejeiçáo da hipótese nula de normalidade dos resíduos não indica normalidade, mas sim que o terceiro e o quarto momento coincidem com os da normal.

Fonte: Elaborada com resultados da pesquisa através do Software GeoDa (versão 1.8.16.4).

Os resultados apresentados na Tabela 1, indicam a existência de autocorrelação espacial dos erros da regressáo, ou seja, é verificado a dependência espacial para os setores agropecuário e de serviços, com o valor da estatística de $I$ de Moran de 0,3625 e 0,1605, respectivamente, ambas significativas ao nível de confiança de $1 \%$.

Diferentemente, a estatística $I$ de Moran para o modelo do setor industrial não foi significativa, indicando que a taxa de crescimento dele náo é influenciada pelo espaço. Este mesmo resultado foi evidenciado com a análise exploratória de dados espaciais. Dessa forma, 
para o setor industrial a análise da convergência absoluta é realizada através do MCRL (Modelo Clássico de Regressão Linear).

O coeficiente da variável PIB Inicial (2000) apresentou sinal negativo (-0,069014) obtido por MCRL, além disso é significante estatisticamente. Sugerindo que houve um processo de convergência absoluta entre os municípios gaúchos no período. Tal resultado indica que os municípios que possuem inicialmente um baixo PIB no setor, em geral, cresceram mais que os que detinham um PIB maior. Desse modo, o crescimento econômico agiu sobre as disparidades de renda entre os municípios, o que beneficiou em maior escala os municípios com menores rendas.

$\mathrm{O}$ setor industrial do RS nos últimos anos vem passando por um processo de desconcentração territorial (LEMOS; CARGNIN, 2014). De certa forma, tal processo contribui para que as disparidades deste setor viessem a diminuir entre os municípios gaúchos, já que o segmento que mais cresceu neste setor ao longo de 2000 a 2010 foi o da indústria de transformação. Esta mesma atividade passou a ganhar relevância nas regióes que eram predominantemente agrícolas, como é o caso da Região Norte, que atualmente se destaca na produção de máquinas e equipamentos agrícolas.

Conforme já destacado, as estimações dos modelos do setor de serviços e agropecuário são autocorrelacionados espacialmente, e dessa forma os demais procedimentos devem ser seguidos. A partir de então, volta-se a análise para os valores dos Multiplicadores de Lagrange (ML), a fim de verificar qual é a melhor especificação espacial do modelo. Para os dois setores (agropecuário e serviços) o teste ML indica que o modelo a ser estimado é o SARMA, mas o mesmo não apresenta significância estatística. Seguindo os demais procedimentos, o ML Erro Espacial foi significativo, indicando que o modelo mais apropriado é o de Erro Espacial (spatial error models - SEM).

Os testes estatísticos indicados por Anselin (2008) apontaram os problemas de não normalidade dos resíduos e de heterocedasticidade, para as estimaçóes do setor agropecuário e de serviços, como é possível identificar através dos testes (Jarque-Bera e Breusch-Pagan), os quais rejeitam a hipótese nula. $\mathrm{O}$ modelo não apresentou problemas de multicolinearide, pois os valores do teste apresentaram-se inferiores a 30, conforme o esperado.

Dessa forma, segundo Almeida (2008), para minimizar tais problemas deve-se proceder com a estimação do modelo SEM através do método de momentos generalizados (MGM), proposto por Kelejiane Prucha (1990). Tal método prescinde a hipótese de normalidade dos erros, dando maior robustez ao modelo estimado. Além disso, a matriz de variância-covariância de White foi utilizada para a estimação dos modelos, pois a mesma é utilizada para corrigir o problema de heterocedasticidade.

A Tabela 2 traz os resultados dos modelos SEM estimados por MGM, a fim de controlar o problema de náo normalidade dos resíduos. 
Tabela 2 - Resultados dos Modelos SEM estimados por MGM para os setores agropecuário e serviços, para a hipótese de convergência absoluta

\begin{tabular}{lll}
\hline Variáveis & Agropecuário & Serviços \\
\hline Variável dependente: & $\ln \left(P I B_{i t} / P I B_{(i t-1)}\right)$ & $\ln \left(P I B_{i t} / P I B_{(i t-1)}\right)$ \\
\hline Constante & 0,7736399 & 0,7790639 \\
& $(0,0021760)$ & $(0,0806137)$ \\
PIB Inicial $(2000)$ & 0,0333324 & 0,1043141 \\
$\lambda$ & $(0,0344391)$ & $(0,0322121)$ \\
& 0,4489447 & 0,3062799 \\
& $(0,0000000)$ & $(0,0000000)$ \\
\hline
\end{tabular}

Fonte: Elaborada com resultados da pesquisa através do Software GeoDaSpace (versão 1.0).

A Tabela 2 apresenta os resultados obtidos pela estimação do modelo SEM, através do método MGM, corrigido para os problemas de não normalidade dos resíduos e heterocedasticidade. $\mathrm{O}$ modelo SEM se caracteriza por apresentar a dependência espacial no termo de erro da regressão, ou seja, o padrão espacial manifestado no termo de erro é dado por efeitos não modelados.

Todos os parâmetros mostraram-se significativos aos níveis de confiança de $1 \%$ e $5 \%$. O coeficiente $\lambda$ é o parâmetro do erro autoregressivo espacial, e o mesmo mostrou-se significativo para os dois modelos (agropecuário e serviços). Tal parâmetro é responsável por indicar que a variável dependente $(y)$ é influenciada pelos choques vindos de todas as regióes, isto é, do sistema como um todo, sendo que as regióes mais próximas são as mais influenciadas, e o choque vai ocorrendo de maneira decrescente.

No caso do setor agropecuário e de serviços, indica que municípios que possuem uma renda inicial baixa influenciam tanto o seu crescimento como dos municípios vizinhos. Além disso, como a dependência espacial foi detectada através dos resíduos, existem fatores não modelados que podem estar influenciando o processo de divergência de renda.

O parâmetro positivo do PIB inicial indica a presença de divergência da taxa de crescimento da renda do setor agropecuário nos municípios gaúchos, já que a expectativa proposta pela literatura é de que o coeficiente assuma valor negativo. Tal resultado mostra que no decorrer dos anos houve um aumento da desigualdade da renda deste setor entre os municípios gaúchos, indicando que os municípios que possuem inicialmente uma renda maior estão crescendo em maior proporção do que os com menor renda.

Os efeitos marginais do PIB inicial sobre a variável dependente dos dois setores é de 0,033 para o setor agropecuário e de 0,1043 para o setor de serviços. É possível observar que a renda inicial exerce menor efeito sobre a taxa de crescimento do PIB agropecuário do que em relação ao do setor de serviços. Com a finalidade de identificar os demais aspectos que possam influenciar no processo de convergência, são estimadas as regressóes para testar a hipótese de convergência condicional. 
$\mathrm{Na}$ Tabela 3, tem-se o modelo de regressão para a convergência condicional. Nesse caso, a convergência depende do ponto de partida, ou seja, os municípios crescerão mais rápido quanto mais distantes estiverem do estado estacionário. Neste modelo foram acrescentadas as variáveis consumo de eletricidade em 2000 para cada setor (proxy do capital físico), taxa de crescimento do pessoal ocupado (para a força de trabalho) e o estoque de capital humano (para o capital humano), a fim de verificar se a inclusão destas variáveis influenciaria a velocidade de convergência.

A estimação dos modelos com a finalidade de testar a hipótese de convergência condicional seguiu os mesmos critérios apresentados para estimação dos modelos de convergência absoluta. A matriz de pesos espaciais que apresentou a melhor estatística $I$ de Moran foi a de $k=2$ vizinhos. Os resultados obtidos pela estimação dos modelos por MQO estấo apresentados na Tabela 3.

Tabela 3 - Resultados dos Modelos estimados por MQO para os setores agropecuário, industrial e serviços, para a hipótese de convergência condicional

\begin{tabular}{|c|c|c|c|}
\hline Variáveis & Agropecuário & Industrial & Serviços \\
\hline \multicolumn{2}{|c|}{ Variável dependente: $\ln \left(P I B_{i t} / P I B_{(i t-1)}\right)$} & $\ln \left(P I B_{i t} / P I B_{(i t-1)}\right)$ & $\ln \left(P I B_{i t} / P I B_{(i t-1)}\right)$ \\
\hline \multirow{2}{*}{ Constante } & 0,471218 & 2,33016 & 0,471218 \\
\hline & $(0,00000)$ & $(0,00000)$ & $(0,00000)$ \\
\hline \multirow[t]{2}{*}{ PIB Inicial (2000) } & 0,0301097 & $-0,0583468$ & 0,1455 \\
\hline & $(0,00423)$ & $(0,09006)$ & $(0,00000)$ \\
\hline \multirow{2}{*}{ Capital Físico } & 0,245185 & $-0,0333346$ & 0,018908 \\
\hline & $(0,00067)$ & $(0,15198)$ & $(0,81118)$ \\
\hline \multirow[t]{2}{*}{ Força de Trabalho } & 0,91180 & $-0,357907$ & $-7,07809$ \\
\hline & $(0,00086)$ & $(0,00000)$ & $(0,00000)$ \\
\hline \multirow[t]{2}{*}{ Capital Humano } & 0,0373441 & 0,789172 & 0,0670222 \\
\hline & $(0,03538)$ & $(0,05164)$ & $(0,04413)$ \\
\hline AIC & 334,586 & 935,113 & 197,922 \\
\hline SC & 355,36 & 955,885 & 177,147 \\
\hline I de Moran & 37,172 & 0,8666 & 2,2879 \\
\hline \multirow[t]{2}{*}{ ML - Defasagem } & 70,0283 & 0,7770 & 2,7502 \\
\hline & $(0,00000)$ & $(0,37807)$ & $(0,09724)$ \\
\hline \multirow[t]{2}{*}{ MLR - Defasagem } & 0,0036 & 0,3390 & 0,0017 \\
\hline & $(0,95199)$ & $(0,56042)$ & $(0,96734)$ \\
\hline \multirow[t]{2}{*}{ ML - Erro } & 73,9749 & 0,5400 & 4,8936 \\
\hline & $(0,0000)$ & $(0,46243)$ & $(0,02696)$ \\
\hline \multirow[t]{2}{*}{ MLR - Erro } & 3,9502 & 0,1020 & 2,1450 \\
\hline & $(0,04686)$ & $(0,74944)$ & $(0,14303)$ \\
\hline \multirow[t]{2}{*}{ ML SARMA } & 72,8623 & 0,4845 & 4,4430 \\
\hline & $(0,00000)$ & $(0,78487)$ & $(0,6578)$ \\
\hline \multirow[t]{2}{*}{ Teste Breusch-Pagan } & 88,5806 & 5,1084 & 9,0216 \\
\hline & $(0,00000)$ & $(0,27635)$ & $(0,06056)$ \\
\hline \multirow[t]{2}{*}{ Teste Jarque-Bera } & 34,2392 & 136,8262 & 298,0351 \\
\hline & $(0,0000)$ & $(0,0000)$ & $(0,0000)$ \\
\hline Multicolinearidade & 30,36 & 28,42 & 27,07 \\
\hline
\end{tabular}

Fonte: Elaborada com resultados da pesquisa através do Software GeoDa (versão 1.8.16.4). 
Diante dos resultados obtidos, percebe-se novamente que o setor agropecuário e de serviços demonstram estar autocorrelacionados espacialmente, como é possível observar através da estatística $I$ de Moran, e rejeita-se a hipótese de aleatoriedade nos dois modelos, com o nível de significância de $1 \%$ para ambos. Os testes de ML indicam que a maneira mais adequada de corrigir a dependência espacial é pela estimação do modelo SEM.

O setor industrial não segue nenhum padrão espacial, sendo a estimação mais adequada através do MCRL, sendo novamente o único a indicar um processo de convergência. $\mathrm{O}$ coeficiente do PIB inicial apresentou sinal negativo, conforme Barro e Sala-i-Martin (1992), existindo um processo de convergência. Portanto, pode-se inferir que o processo de convergência de renda dá-se de forma que os municípios estáo convergindo para seus próprios estados estacionários, em que os mais distantes do equilíbrio crescem a uma taxa maior, embora tal fenômeno não esteja ocorrendo com a influência do espaço.

A especificação do modelo para testar a hipótese de convergência condicional visa diminuir o viés de variável omitida com a introdução de variáveis associadas ao capital físico, capital humano e crescimento da força de trabalho de cada município, controlando assim as diferenças estruturais relevantes no período inicial.

Para o setor industrial, as variáveis incluídas que foram significativas aos níveis de $10 \%$ e $1 \%$, são o capital humano e força de trabalho, respectivamente. Além disso, apresentaram o sinal esperado de acordo com a teoria de Lucas (1988) e Solow (1956). O capital humano, o qual representa o nível do pessoal ocupado no setor industrial, indica que quão maior for o percentual de trabalhadores no setor com maior nível de instruçáo, maior é o crescimento do setor. Além disso, tal variável foi a que apresenta o maior coeficiente, indicando a relevância da educaçáo para o crescimento do setor no decorrer do período analisado.

A variável força de trabalho foi significativa ao nível de $1 \%$. A mesma apresentou sinal negativo, indicando que o aumento do pessoal ocupado no setor náo contribui para o crescimento do mesmo. Tal resultado corrobora com o exposto no modelo de Solow (1956), o qual supóe que o aumento da força de trabalho prejudica o processo de convergência, pois como há mais trabalhadores disponíveis, o capital empregado por trabalhador tenderá a ser menor, bem como os níveis de salários.

Amorin, Scalco e Braga (2008), ao realizarem um estudo sobre os três setores da economia, constataram que há tendência à convergência absoluta da renda para os setores da indústria e serviços. Além disso, verificaram que o padráo dessa convergência difere muito entre esses dois setores, sendo que a indústria tem uma velocidade de convergência muito maior do que o setor de serviços. No entanto, para o setor agropecuário nenhuma das hipóteses de convergência foi confirmada.

Quanto ao ajustamento dos modelos, para o setor agropecuário os testes indicam a presença de heterocedasticidade e não normalidade dos resíduos. Já para o setor de serviços, o modelo indicou apenas a não normalidade dos resíduos. A fim de corrigir tais problemas, seguiu-se novamente o proposto por Kelejiane e Prucha (1990), estimar o modelo por MGM. Novamente a matriz de variância-covariância de White foi utilizada para correçáo do problema de heterocedasticidade. 
Tabela 4 - Resultados dos Modelos SEM estimados por MGM para os setores agropecuário e serviços, para a convergência condicional

\begin{tabular}{lll}
\hline Variáveis & Agropecuário & Serviços \\
\hline Variável dependente: & $\ln \left(P I B_{i t} / P I B_{(i t-1)}\right)$ & $\ln \left(P I B_{i t} / P_{\left(B_{(i t-1)}\right)}\right.$ \\
\hline Constante & 0,7719140 & 0,4800567 \\
& $(0,0248412)$ & $(0,0135280)$ \\
PIB Inicial (2000) & 0,0325322 & 0,169899 \\
& $(0,0289206)$ & $(0,0322121)$ \\
Capital Físico & 0,2315521 & 0,0040659 \\
& $(0,0000658)$ & $(0,9592710)$ \\
Força de Trabalho & 0,9856351 & $-7,0795411$ \\
& $(0,0026236)$ & $(0,0000000)$ \\
Capital Humano & 0,0362188 & 0,0686415 \\
$\lambda$ & $(0,0786160)$ & $(0,0340485)$ \\
& 0,3537600 & 0,1059812 \\
& $(0,0000000)$ & $(0,0186150)$ \\
\hline
\end{tabular}

Fonte: Elaborado com resultados da pesquisa através do Software GeoDaSpace (versão 1.0).

A Tabela 4 apresenta os resultados dos modelos SEM para os dois setores, sendo que o parâmetro $\lambda$ foi significativo para ambos os modelos, indicando que parte da dependência espacial náo modelada se manifesta no padrão do erro aleatório entre regióes vizinhas. Embora tenham sido incluídas novas variáveis com o objetivo de explicar o processo de crescimento dos diferentes setores, os resultados apontam que outros aspectos podem estar influenciando espacialmente a trajetória de crescimento dos mesmos.

A variável PIB inicial apresentou significância ao nível de $5 \%$ para os dois modelos, porém o sinal esperado não foi evidenciado, ou seja, o resultado aponta para a não convergência de renda dos setores e nem mesmo para o seu próprio estado estacionário. É possível verificar que novamente o PIB inicial age de maneira diferente entre os setores (agropecuário e serviços). A mesma apresenta o maior coeficiente para o setor de serviços, indicando que os municípios que possuem inicialmente uma renda maior neste setor estão apresentando maiores taxas de crescimento.

O capital físico não é significativo para o crescimento do setor de serviços. No entanto, para o setor agropecuário a variável é estatisticamente significativa, demonstrando que o aumento do investimento em capital físico irá influenciar positivamente o processo de crescimento desse setor.

A variável capital humano passou a ser incluída nos modelos de crescimento por Mankin, Roner e Weil (1992) e Lucas (1988), sob a hipótese de que a exclusão da mesma estaria superestimando o efeito da acumulação de capital físico sobre o crescimento. Dessa maneira, o processo de crescimento seria determinado pela acumulaçáo de capital físico e humano, juntamente com a produção de conhecimento criado por pesquisa e desenvolvimento. 
Contrariamente ao modelo neoclássico de Solow (1956), a teoria de crescimento endógeno náo acredita na existência de um estado estacionário determinado, ou seja, o capital humano somado a demais fatores irá contribuir para o crescimento econômico sem limites pré- definidos.

Os parâmetros obtidos dessa variável nos modelos da Tabela 4 apresentaram o sinal esperado (positivo), indicando que um aumento no nível de educação do pessoal ocupado nos setores agropecuário e de serviços influencia positivamente no aumento da renda. É importante ressaltar que tal efeito demonstra ser maior no setor de serviços, visto que ele é responsável por grande parte dos empregos no RS, e o pessoal ocupado exibe um nível maior de instruçáo quando comparado ao setor agropecuário.

A força de trabalho, apresentada como a taxa de crescimento do pessoal ocupado no setor, foi significativa para os dois modelos, embora o sinal esperado (negativo) tenha sido obtido apenas para o setor de serviços. De acordo com a vertente neoclássica, dado o aumento da força de trabalho reduz a relação capital por trabalhador, tendo um efeito negativo no processo de crescimento.

Algumas evidências empíricas encontradas para os municípios gaúchos têm apontado para a convergência de renda absoluta e condicional, como é o caso dos trabalhos desenvolvidos por Fantinel (2016) e Casagrande, Hoeckel e Dos Santos (2017). No entanto, esses estudos levam em consideração na análise a renda agregada, não havendo distinção entre os setores. Diferentemente deles, os resultados obtidos no trabalho apontam para um crescimento heterogêneo entre os setores nos municípios gaúchos, ou seja, eles não seguem o mesmo padrão.

Outro aspecto importante a ser levantado diz respeito a não identificação da hipótese de convergência absoluta e condicional para os setores agropecuário e serviços, haja visto que o Estado apresenta estruturas produtivas diferenciadas, e que elas resultam da especialização em determinada atividade na região ou município. Como por exemplo, o caso da vitivinicultura nos municípios da Serra, e a produção de soja em Palmeira das Missóes e Cruz Alta (FEE, 2017).

\section{CONCLUSÃO}

O presente estudo traz uma melhor compreensão do processo de crescimento econômico dos municípios do Rio Grande do Sul para o período de 2000 a 2010, utilizandose na análise as rendas dos diferentes setores da economia (agropecuário, industrial e serviços).

Através da AEDE, da estatística I de Moran global, foi possível verificar que a taxa de crescimento nos setores agropecuário e serviços são influenciados pelo espaço. A estatística global positiva para ambos demonstrou que os municípios que possuem uma alta taxa de crescimento são vizinhos de municípios com a mesma característica, indicando um efeito spillover. No entanto, a estatística $I$ de Moran não foi significativa para o setor industrial, indicando que a taxa de crescimento deste setor náo é influenciada pela taxa de crescimento das regióes vizinhas. 
O setor agropecuário foi o que apresentou maior formação de clusters no quadrante Alto-Alto, ou seja, municípios que possuem elevada taxa de crescimento são vizinhos de municípios detentores da mesma característica. A localização dos mesmos se deu principalmente na regiáo de Cruz Alta e da Campanha Ocidental, regióes marcadas pelo cultivo de soja, pecuária e arroz, atividades passíveis de imitação.

O setor industrial é marcado por apresentar o maior número de clusters no quadrante Baixo-Baixo, no qual municípios com baixa taxa de crescimento também são vizinhos de municípios com baixa taxa de crescimento. O setor industrial é mais concentrado na Região Metropolitana do Estado, e sua participação em algumas regiôes, como na Região Norte, é praticamente insignificante. Tal fato contribuiu para um número elevado de municípios não apresentaram significância, bem como estarem concentrados no quadrante BB.

A análise da autocorrelação local para o setor de serviços foi mais equilibrada em termos de formação dos clusters nos quadrantes AA e BB, identificando diferentes padróes de crescimento do setor no Estado. A Regiáo Sul é marcada por baixas taxas de crescimento com vizinhos com a mesma característica, enquanto a Regiáo Centro-Oeste possui municípios e vizinhos com altas taxas de crescimento.

Os resultados obtidos com a análise exploratória de dados serviram de suporte para estimação dos modelos econométricos. A AEDE identificou que o crescimento dos setores acontece de maneira diferente e que quando são analisados de forma agregada as suas características incomuns podem ser ofuscadas. Além disso, mostra que é importante levar em consideração os aspectos espaciais no processo de crescimento econômico.

De acordo com os testes de convergência realizados, é possível afirmar que o setor industrial foi o único a indicar a ocorrência de um processo de convergência, de modo que os municípios com menor renda inicial cresceram mais do que aqueles que possuem um nível de renda maior. A hipótese de convergência condicional e absoluta não se confirmou para os setores agropecuário e serviços, indicando que não está ocorrendo diminuição nas disparidades entre os municípios.

Um dos principais resultados obtidos com a realização deste trabalho apontam para não a aceitação da hipótese de convergência absoluta e condicional nos setores agropecuário e serviços, demonstrando que as divergências estão aumentando no decorrer do período analisado. Diversos são os fatores que podem estar contribuindo para o acirramento dessas desigualdades, a heterogeneidade dos municípios gaúchos, a especialização em diferentes sistemas produtivos, fatores institucionais e até mesmo fatores geográficos e climáticos no caso da agropecuária.

Além disso, a estimação dos modelos econométricos espaciais indicaram que existem ainda fatores que não foram modelados e que contribuem para explicar o processo de crescimento econômico dos municípios. Dessa forma, trabalhos futuros poderão incluir demais variáveis e também realizar uma comparação de diferentes métodos para estimar a hipótese de convergência. 


\section{REFERÊNCIAS}

ABRAMOVITZ, M. Catching up, forging ahead, and falling behind. The Journal of Economic History, v. 46, n. 02, p. 385-406, 1986. Disponível em: < http://www.jstor. org/stable/2122171 >. Acesso em: 10 jun. 2017.

ALMEIDA, E. S. de; PEROBELLI, F. S.; FERREIRA, P. G. C. Existe convergência espacial da produtividade agrícola no Brasil?. Revista de Economia e Sociologia Rural, v. 46, n. 1, p. 31-52, 2008. Disponível em:< http://dx.doi.org/10.1590/S0103$20032008000100002>$. Acesso em: 5 maio 2017.

ALMEIDA, E. S. Econometria Espacial Aplicada. 1. Ed. Campinas: Editora Alínea, 2012. $498 \mathrm{p}$.

ANSELIN, L. Exploring Spatial Data with GeoDa: A Workbook. Copyright, 2005.

ANSELIN, L. Spatial econometrics: methods and models. v. 4. Springer Science \& Business Media, 2013. Disponível em: < https://books.google.com.br/books?hl=pt-BR\&lr $=\& \mathrm{id}=\mathrm{G} 47 \mathrm{tCAAAQBAJ} \& \mathrm{oi}=$ fnd $\& \mathrm{pg}=\mathrm{PR} 14 \& \mathrm{dq}=$ Spatial + Econometrics + Luc + Anselin* $\&$ ots=axfSbTL4tl\&sig=67msRFfyWcTxZyF-MoJW1nwN0>. Acesso em: 10 jul. 2017.

BARRETO, R. C. S.; ALMEIDA, E. S de. A contribuição do capital humano para crescimento econômico e convergência espacial do PIB per capita no Ceará. Economia do Ceará em Debate. Fortaleza: IPECE, p. 10-26, 2008. Disponível em: http://www.ipece. ce.gov.br/publicacoes/Encontro_Economia_Ceara_Debate_2008.pdf\#page=13> . Acesso: 4 jun. 2017.

BARRO, R. J.; SALA-I-MARTIN, X. Convergence across states and regions. Brookings Papers on Economic Activity. p. 107-181, 1991. Disponível em:< https://www. brookings.edu/wpcontent/uploads/1991/01/1991a_bpea_barro_salaimartin_blanchard_ hall.pdf >. Acesso em: 23 nov. 2017.

BARRO, R.; SALA-I-MARTIN, X. Convergence.Journal of Political Economy. The University of Chicago. v. 100, n. 2, p. 223-251, 1992. Disponível em: < https://dash. harvard.edu/bitstream/handle/1/3451299/barro_convergence.pdf?sequence $=4>$. Acesso em: 15 set. 2017.

BAUMOL W.J. Productivity growth, convergence, and welfare: what the long-run data how. The American Economic Review. v. 76, n.5 p. 1072-1085, Dez./1986. Diponível em: < http://www.jstor.org/stable/1816469?seq=1\#page_scan_tab_contents $>$. Acesso em: 7 jul. 2017.

BAUMONT, C.; ERTUR C.; LE GALLO, J. Geographic spillover and growth: a spatial econometric analysis for European regions. LATEC-Document de travail, Economie, v. 
7, Jun./ 2000. Disponível em: <http://lara.inist.fr/bitstream/handle/2332/2307/LATECDT_00-07.pdf?sequence=1>. Acesso em: 14 jun. 2017.

CASAGRANDE, D. L.; HOECKEL, P. H. de O.; DOS SANTOS, C. A. P. Convergência do PIB per capita no rio grande do sul: uma análise de 2001 a 2013. Revista Brasileira de Estudos Regionais e Urbanos, v. 11, n. 3, p. 358-383, 2017. Disponível em: < https://www.revistaaber.org.br/rberu/article/view/198> . Acesso em: 20 dez. 2017.

DA SILVA, I. M. et al. Associação de dados espaciais: uma análise exploratória para desenvolvimento econômico do estado do Pará. Revista Teoria e Evidência Econômica. Ano 17, n. 36, p. 63-79, jan./jun. 2011. Disponível em:< http://seer.upf.br/index.php/ rtee/article/viewFile/4242/2731>. Acesso em: 20 dez. 2017.

ESPERIDIÃO, F. Capital Humano e convergência na regiáo sul: uma análise a partir das microrregióes. 2008. Xv 329 f. Tese (Programa de Mestrado e Doutorado em Desenvolvimento Econômico - CMDE) Universidade Federal do Paraná, Curitiba, PR, 2008. Disponível em:<http://www.economia.ufpr.br/Teses\%20Doutorado/21\%20\%20 FERNANDA\%20ESPERIDI\%C3\%83O.pdf>. Acesso: 7 abr. 2017.

FEEDADOS. Fundação de Economia e Estatística. Dados e Mapas. Disponível em: < http://feedados.fee.tche.br/feedados/>. Acesso em: 6 abr. 2017.

\section{FIALKOW, J. C. Determinantes regionais da desigualdade de renda no Rio Grande} do Sul, 2000-2010. 2014. 94 p. Dissertação (Mestrado em Economia) -Centro de Desenvolvimento e Planejamento Regional da Faculdade de Ciências Econômicas da Universidade Federal de Minas Gerais, Minas Gerais, 2014. Disponível em: <: https:// www.cedeplar.ufmg.br/.../78-2014?.determinantes-regionais-da-desigualdade-..> . Acesso em: 10 dez. 2017.

FIORI, T.P. Desigualdades regionais no Rio Grande do Sul. Carta Conjuntura FEE. v. 21, no 8, 2012. Disponível em:<http://carta.fee.tche.br/article/desigualdades-regionaisno-rio-grande-do-sul/>. Acesso em: 20 dez. 2017.

INSTITUTO BRASILEIRO DE GEOGRAFIA E ESTATÍSTICA (IBGE), Disponível em: < http://www.sidra.ibge.gov.br>. Acesso em: 07 abr. 2017.

IPEADATA, Instituto de Pesquisa Aplicada. Dados macroeconômicos e regionais. Disponível em: http://www. ipeadata. gov. br>. Acesso em: 16 dez. 2017.

LEMOS, B. O.; CARGNIN, A. P. Características da distribuição territorial da indústria de transformação no Estado do Rio Grande do Sul. Textos para Discussáo FEE. n. 126, 2014. Disponível em: < https://www.fee.rs.gov.br/wp-content/ uploads/2014/10/20141015td-126-caracteristicas-da-distribuicao-territorial-da-industriade-transformacao-no-estado-do-rio-grande-do-sul.pdf $>$.Acesso em: $10 \mathrm{dez} .2017$. 
LUCAS, R. E. JR. On the mechanics of economic development. Journal of Monetary Economics, v. 22, n. 1, p. 3-42, Jul./1988. Disponível em: https://www. parisschoolofeconomics.eu/docs/darcillonthibault/lucasmechanicseconomicgrowth.pdf.>. Acesso em: 15 jul. 2017.

MANKIW, N. G.; ROMER, D.; WEIL, D. N. A contribution to the empirics of economic growth. The quarterly journal of economics, v. 107, n. 2, p. 407-437, May/1992. Disponível em: <https://academic.oup.com/qje/articleabstract/107/2/407/1838296> Acesso em: 18 dez. 2017.

MENEZES, G.; FEIJÓ, F. T. O contraste econômico entre as metades Sul e Norte do Rio Grande do Sul: uma aplicaçáo do modelo da base econômica. ENCONTRO DE ECONOMIA GAÚCHA, v. 4, p. 1-20, 2008.

QUAH, D. Empirics for economic growth and convergence. European Economic Review. v. 40, p. 1353-75, 1995. Disponível em: < http://citeseerx.ist.psu.edu/viewdoc/ download?doi=10.1.1.177.5827\&rep=rep1\&type=pdf> Acesso em: 10 dez. 2017.

RANDS, A. B. Desigualdades regionais no Brasil: natureza, causas, origens e soluçáo. Rio de Janeiro: Elsevier, 2011.

RIBEIRO, E. C. B de A. Convergência de renda local entre os municípios brasileiros para o período 2000 a 2005. 2010. 140 p. Dissertaçâo apresentada (Programa de Mestrado em Economia Aplicada) - Universidade Federal de Juiz de Fora, Juiz de Fora, MG, 2010. Disponível em: <http://bdtd.ibict.br/vufind/Record/UFJF_ a74b62f697842d49e4e284b733d9c158> Acesso em: 6 jun. 2017.

SALA-I-MARTIN, X. The Classical Approach to Convergence Analysis. In: ALVES, Luiz Fernando; FONTES, Rosa. Convergence Clubs in Minas Gerais State, Brazil. 1992. Disponível em: http://papers.ssrn.com/sol3/papers.cfm?abstract_id=276905. Acesso em: 10 mar. 2017. 